18

\title{
Синтез нанонитей оксида индия-цинка и исследование их чувствительности к ультрафиолетовому излучению
}

\author{
(C) Н.П. Маркова, О.Я. Березина, А.Л. Пергамент, Е.Н. Колобова, В.П. Малиненко, А.Ю. Алексеев \\ Петрозаводский государственный университет, \\ 185910 Петрозаводск, Россия \\ e-mail: berezina@petrsu.ru
}

Поступила в редакцию 02.04.2019 г.

В окончательной редакции 02.04.2019 г.

Принята к публикации 23.04.2019 г.

Нанонити оксида индия-цинка (IZO) синтезированы методом электроспиннинга на подложках $\mathrm{Si}-\mathrm{SiO}_{2}$. Размеры, морфология, кристаллическая структура и состав нанонитей исследованы методами сканирующей электронной микроскопии, атомно-силовой микроскопии, энергодисперсионного рентгеновского анализа и рентгеновской дифракции. Представлены результаты изучения электрических свойств нановолокон, а также их чувствительности к ультрафиолетовому излучению $(У \Phi)$ в зависимости от соотношения концентраций In и Zn. Показано, что наибольшая чувствительность к УФ наблюдается при содержании индия около 50 ат.\%. Приращение фототока относительно темнового тока составляет в этом случае более 4 порядков величины. Время отклика и восстановления составляет 6 и $50 \mathrm{~s}$ соответственно. Полученные результаты показывают, что нановолокна IZO могут найти применение в качестве УФ датчиков с улучшенными характеристиками.

Ключевые слова: оксид индия-цинка, нанонити, чувствительность к УФ излучению, электроспиннинг.

DOI: $10.21883 /$ OS.2019.09.48207.130-19

\section{Введение}

Оксид цинка - широкозонный полупроводник, относящийся к группе прозрачных проводящих оксидов, обладающий уникальными электрическими и оптическими свойствами $[1,2]$.

Оксид цинка характеризуется высокой чувствительностью электрофизических свойств к изменению состояния окружающей среды и является одним из наиболее распространенных материалов для газовых сенсоров $[3,4]$, однако низкая проводимость недопированного оксида цинка затрудняет его применение и приводит к необходимости понижения сопротивления функционального материала. Одним из способов увеличения проводимости $\mathrm{ZnO}$ является легирование элементами III группы. Катионы $\mathrm{M}^{3+}$ являются донорными примесями, их встраивание в структуру оксида цинка в катионные позиции цинка приводит к увеличению концентрации свободных носителей заряда. Выбор допирующей примеси проводится на основе сравнения ионных радиусов цинка и трехвалентного катиона. Из всех элементов III группы наиболее близкими значениями эффективных ионных радиусов к радиусу $\mathrm{Zn}^{2+}$ обладают $\mathrm{Ga}^{3+}$ и $\mathrm{In}^{3+}$, которые наиболее часто используются на практике [4]. В настоящей работе был использован катион $\mathrm{In}^{3+}$.

Смешанные оксиды на основе $\mathrm{ZnO}$ (с добавками In, $\mathrm{Ga}$ и $\mathrm{Al})$ находят применение в качестве прозрачных проводящих покрытий $[2,4,5]$, материалов тонкопленочных транзисторов для прозрачной электроники [6-9] и сенсоров [4,10-14].

Чувствительность IZO к ультрафиолетовому излучению (УФ) изучалась ранее в работах [13,14]. Так, в [14] разработан простой метод изготовления УФ фотоприемника на основе легированного индием $\mathrm{ZnO}$ на стеклянной подложке. Наноструктуры IZO были выращены жидкофазным методом, их средняя длина и диаметр составляли $3.06 \mu \mathrm{m}$ и $38 \mathrm{~nm}$ соответственно. При смещении $1 \mathrm{~V}$ отношение фототока к темновому току составляло 740 при облучении УФ светом на длине волны $365 \mathrm{~nm}$. Образец показал быструю реакцию и время восстановления: времена нарастания и спада фототока составили соответственно 3.02 и $1.53 \mathrm{~s}$ [14].

Таким образом, как видно из представленных литературных данных, области практического применения легированого оксида цинка, включая IZO, весьма обширны. Перспективы его широкого использования, в первую очередь, связаны с разработкой надежных, простых и дешевых методов получения материалов с контролируемыми свойствами и в широком диапазоне вариации соотношения концентраций индия и цинка. Причем чувствительность сенсоров, изготовленных в виде наноструктур, существенно выше, чем пленочных из-за большей площади свободной поверхности.

В настоящей работе описано получение нанонитей IZO методом электроспиннинга и представлены результаты исследования их свойств и чувствительности к УФ излучению в зависимости от состава (соотношения концентраций индия и цинка).

\section{Эксперимент: получение образцов, их морфология, состав и структура}

Синтез нанонитей оксида индия-цинка проводился методом электроспиннинга. Электроспиннинг является 
Таблица 1. Обозначения и состав полученных образцов

\begin{tabular}{c|c|c|c|c|c|c|c|c|c}
\hline & IZO1 & IZO2 & IZO3 & IZO4 & IZO5 & IZO6 & IZO7 & IZO8 & IZO9 \\
\hline$\%$ In & 100 & 95 & 80 & 60 & 50 & 40 & 20 & 10 & 0 \\
$\% Z n$ & 0 & 5 & 20 & 40 & 50 & 60 & 80 & 90 & 100
\end{tabular}

одной из разновидностей золь-гель метода. Полимерный раствор выдавливается через капилляр, затем капля в высоковольтном электростатическом поле расщепляется на нити, которые осаждаются на заземленный коллектор [15].

Для получения нанонитей оксида индия-цинка к раствору ацетата цинка двухводного $\mathrm{Zn}\left(\mathrm{CH}_{3} \mathrm{COO}\right)_{2} \cdot 2 \mathrm{H}_{2} \mathrm{O}$ в этаноле добавляли нитрат индия $\mathrm{In}\left(\mathrm{NO}_{3}\right)_{3} \cdot 4.5 \mathrm{H}_{2} \mathrm{O}$. $\mathrm{B}$ качестве полимера применялся высокомолекулярный поливинипирролидон PVP $\left(\mathrm{Mr}=1.3 \cdot 10^{6} \mathrm{~g} / \mathrm{mol}\right)$. Общая масса солей в растворе составляла $0.6 \mathrm{~g}$. Объем этанола $8 \mathrm{ml}$, масса PVP - $0.6 \mathrm{~g}$. Смесь перемешивалась на магнитной мешалке в течение двух часов. Состав приготовленных растворов с различным атомным содержанием In и $\mathrm{Zn}$ и обозначения соответствующих образцов представлены в табл. 1.

Готовый прекурсор помещался в шприц, который закреплялся в шприцевом насосе NE-300. Между иглой шприца и коллектором из алюминиевой фольги создавалась разность потенциалов $15-18 \mathrm{kV}$ при помощи источника высокого напряжения ИНВР-30/5. Расстояние от сопла иглы до коллектора составляло $15 \mathrm{~cm}$. Скорость подачи жидкости менялась в диапазоне $0.3-0.5 \mathrm{ml} / \mathrm{h}$. Нанонити наносились на подложки $\mathrm{Si}-\mathrm{SiO}_{2}$ площадью $2-5 \mathrm{~cm}^{2}$, которые располагались на коллекторе.

После нанесения нанонити отжигались в программируемой печи OTF-1200Х. Целью отжига являлось удаление из них органических соединений и формирование устойчивых соединений оксида индия-цинка. Отжиг нитей производился на воздухе при $600^{\circ} \mathrm{C}$ в течение $5 \mathrm{~h}$. Скорость нагрева и охлаждения составляла $5^{\circ} \mathrm{C} / \mathrm{min}$. В работе [16] было показано, что данный способ отжига способствует наилучшей кристаллизации нитей.

Диаметр нитей до и после отжига оценивался с помощью сканирующего электронного микроскопа Hitachi SU 1510. Диаметр нанонитей до отжига колеблется в пределах 250-320 nm (рис. 1, a), а после отжига диаметр уменьшается до 50-100 nm (рис. 1, b).

Морфология поверхности полученных нитей исследовалась с помощью атомно-силового микроскопа СММ-2000 в контактном режиме (рис. 2). В ходе изучения поверхности было установлено, что вертикальный размер нити меньше горизонтального. Причиной деформации, скорее всего, являлся термический отжиг. При горизонтальном размере нити в $100 \mathrm{~nm}$ ее вертикальный размер не превосходит $60 \mathrm{~nm}$.

До и после отжига проводился количественный элементный анализ нанонитей (табл. 2) с помощью приставки энергодисперсионного рентгеновского анализа (EDX)
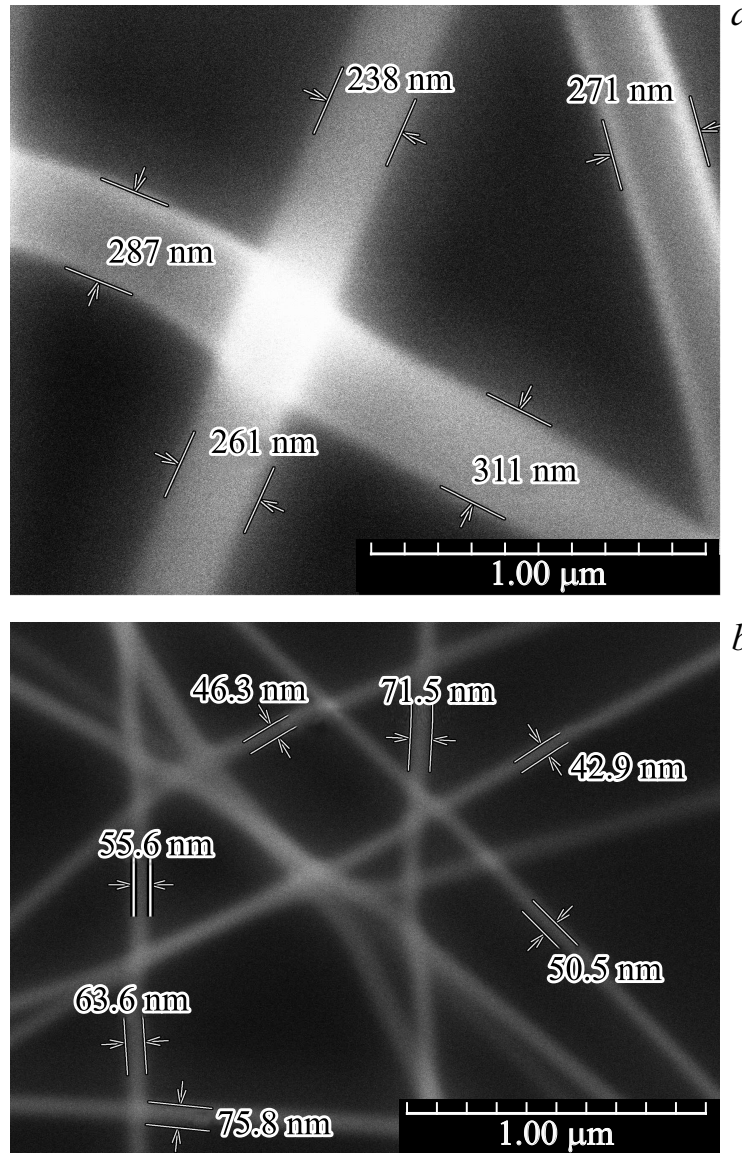

Рис. 1. Изображение нанонитей (увеличение $30000 \mathrm{X})$ : (a) до отжига, $(b)$ после отжига
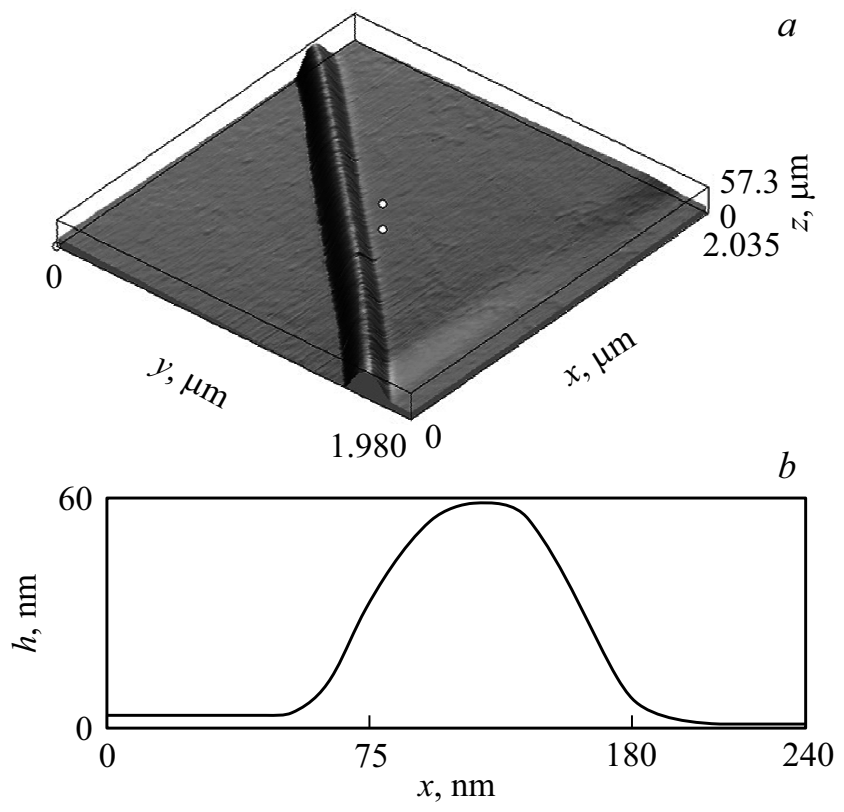

Рис. 2. Трехмерное изображение (вверху) и профиль (внизу) нанонити оксида индия-цинка, полученные с помощью АСМ. 
Таблица 2. Элементный состав нанонитей IZO до и после термообработки

\begin{tabular}{|c|c|c|c|c|c|c|c|c|c|c|c|c|c|c|}
\hline \multirow[b]{2}{*}{ Элемент } & \multicolumn{2}{|c|}{ IZO1 } & \multicolumn{2}{|c|}{$\mathrm{IZO} 2$} & \multicolumn{2}{|c|}{ IZO3 } & \multicolumn{2}{|c|}{ IZO5 } & \multicolumn{2}{|c|}{ IZO6 } & \multicolumn{2}{|c|}{ IZO7 } & \multicolumn{2}{|c|}{ IZO9 } \\
\hline & $\begin{array}{c}\text { До } \\
\text { отжига } \\
\text { at.\% }\end{array}$ & $\begin{array}{c}\text { После } \\
\text { отжига } \\
\text { at.\% }\end{array}$ & $\begin{array}{c}\text { До } \\
\text { отжига } \\
\text { at.\% }\end{array}$ & $\begin{array}{c}\text { После } \\
\text { отжига } \\
\text { at.\% }\end{array}$ & \begin{tabular}{|c|} 
До \\
отжига \\
at.\%
\end{tabular} & $\begin{array}{c}\text { После } \\
\text { отжига } \\
\text { at.\% } \\
\end{array}$ & \begin{tabular}{|c} 
До \\
отжига \\
at.\%
\end{tabular} & \begin{tabular}{|c|} 
После \\
отжига \\
at.\%
\end{tabular} & \begin{tabular}{|c|} 
До \\
отжига \\
at.\% \\
\end{tabular} & \begin{tabular}{|c|} 
После \\
отжига \\
at.\%
\end{tabular} & $\begin{array}{c}\text { До } \\
\text { отжига } \\
\text { at.\% }\end{array}$ & \begin{tabular}{|c|} 
После \\
отжига \\
at.\% \\
\end{tabular} & $\begin{array}{c}\text { До } \\
\text { отжига } \\
\text { at.\% }\end{array}$ & $\begin{array}{c}\text { После } \\
\text { отжига } \\
\text { at.\% }\end{array}$ \\
\hline $\begin{array}{c}\text { Атомное } \\
\text { отношение } \\
\text { In } /(\operatorname{In}+Z n)\end{array}$ & 100 & 100 & 94.9 & 93.6 & 79.8 & 82.1 & 49.7 & 50.7 & 39.9 & 38.7 & 19.4 & 20.0 & 0 & 0 \\
\hline $\mathrm{C}$ & 32.1 & 5.3 & 33.3 & 4.8 & 31 & 7.4 & 33.0 & 7.8 & 36.3 & 8.0 & 42.3 & 7.2 & 44.0 & 9.9 \\
\hline $\mathrm{N}$ & 12.0 & 0 & 11.3 & 0 & 11.4 & 0 & 11.6 & 0 & 9.9 & 0 & 7.0 & 0 & 14.7 & 0 \\
\hline $\mathrm{O}$ & 51.2 & 62.6 & 50.9 & 49.6 & 52.9 & 60.0 & 50.4 & 62.6 & 46.3 & 66.0 & 42.0 & 53.1 & 34.0 & 45.9 \\
\hline In & 4.8 & 32.1 & 4.3 & 42.7 & 3.5 & 26.8 & 2.5 & 15.0 & 3.0 & 10.8 & 1.7 & 7.9 & 0 & 0 \\
\hline $\mathrm{Zn}$ & 0 & 0 & 0.2 & 2.9 & 0.9 & 5.8 & 2.5 & 14.6 & 4.6 & 15.9 & 7.0 & 31.7 & 7.3 & 44.2 \\
\hline
\end{tabular}

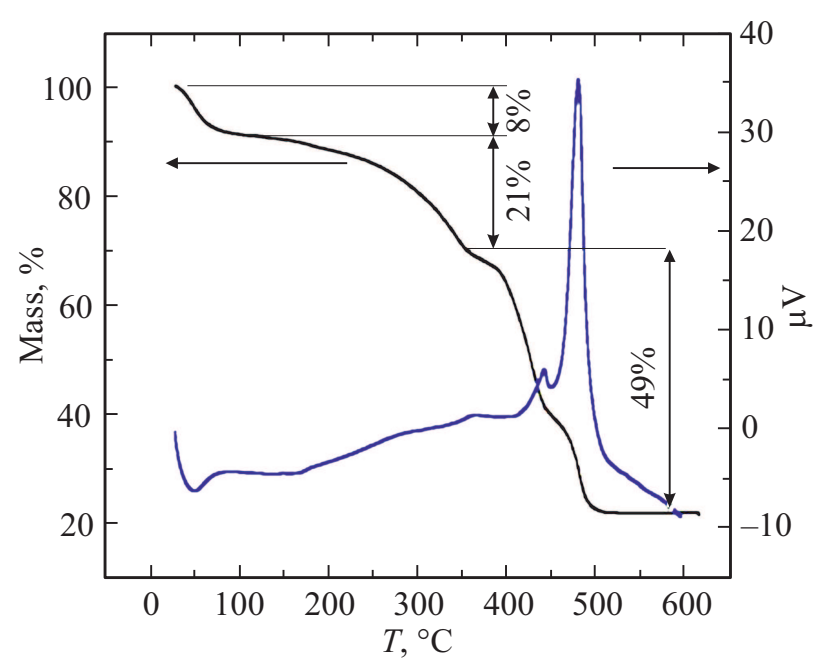

Рис. 3. Результаты ТГА и ДТА.

ThermoScientificUltraDry для сканирующего электронного микроскопа Hitachi SU 1510. Как видно из табл. 2, состав полученных нитей соответствует условиям закладки. После отжига заметно уменьшается количество углерода и исчезает азот, что свидетельствует об уходе органических соединений из нанонитей.

Также были проведены исследования методами дифференциального термического анализа (ДТА) и термогравиметрического анализа (ТГА). Использовалась установка Hitachi STA 7300. Результаты исследований методами ДТА и ТГА приведены на рис. 3.

Нагревание проводили в токе воздуха $(30 \mathrm{ml} / \mathrm{min})$ в интервале температур $40-600^{\circ} \mathrm{C}$ со скоростью нагрева $5^{\circ} \mathrm{C} / \mathrm{min}$. По результатам ТГА можно выделить несколько стадий изменения массы. Первое изменение массы в интервале температур $20-100^{\circ} \mathrm{C}$ связано с процессом испарения воды с поверхности образца, при этом масса образца уменьшается на $8-9 \%$.

В интервале температур $100-350^{\circ} \mathrm{C}$ происходит деградация PVP, что приводит к потере массы еще на $21 \%$. Быстрое изменение массы при температурах $350-470^{\circ} \mathrm{C}$ связано с пиролизом PVP. Общая потеря массы при этом составляет $78 \%$.

В интервале температур $350-470^{\circ} \mathrm{C}$ ярко выражены два пика, которые соответствуют выделению тепла при горении органики. Данные ТГА согласуются с результатами ДТА и демонстрируют, что выбранный режим отжига нитей является оптимальным для полного удаления из нитей PVP и формирования устойчивых соединений оксида индия-цинка.

На рис. 4, $a$ представлена кривая распределения интенсивности рассеяния рентгеновского излучения для

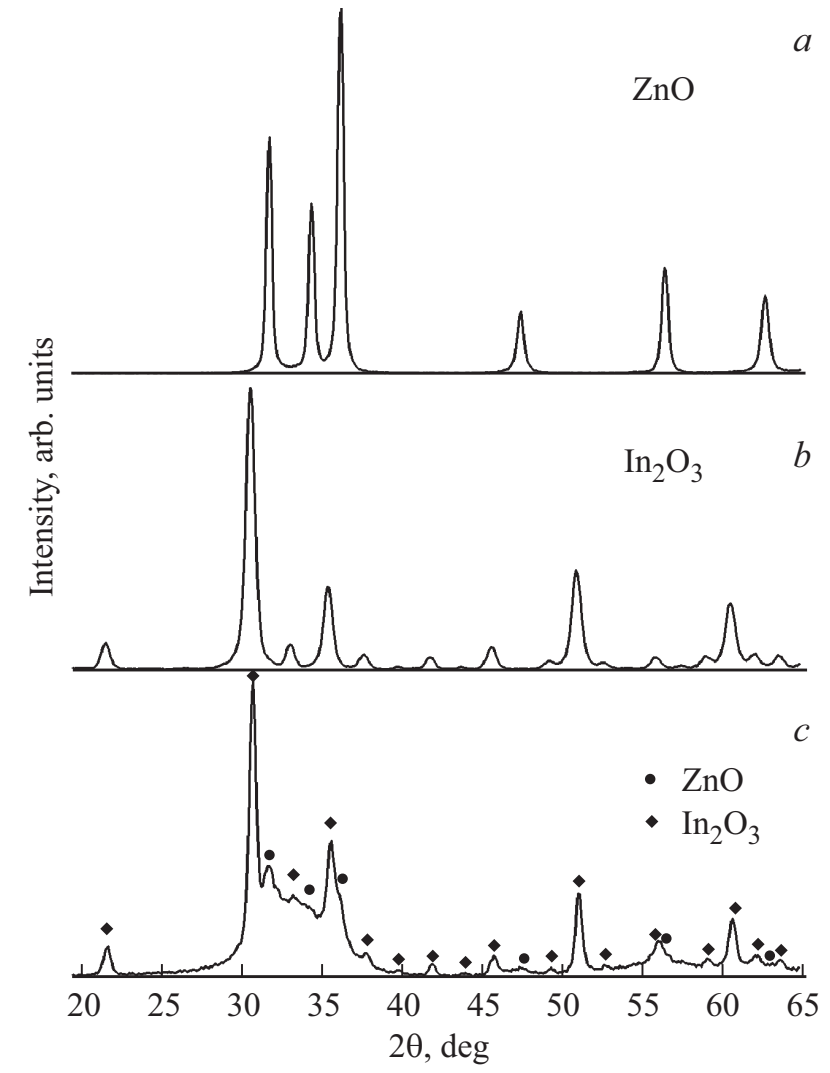

Рис. 4. Рентгенограммы нанонитей после отжига: $\operatorname{IZO9}(a)$, IZO1 $(b)$ и IZO5 $(c)$. 

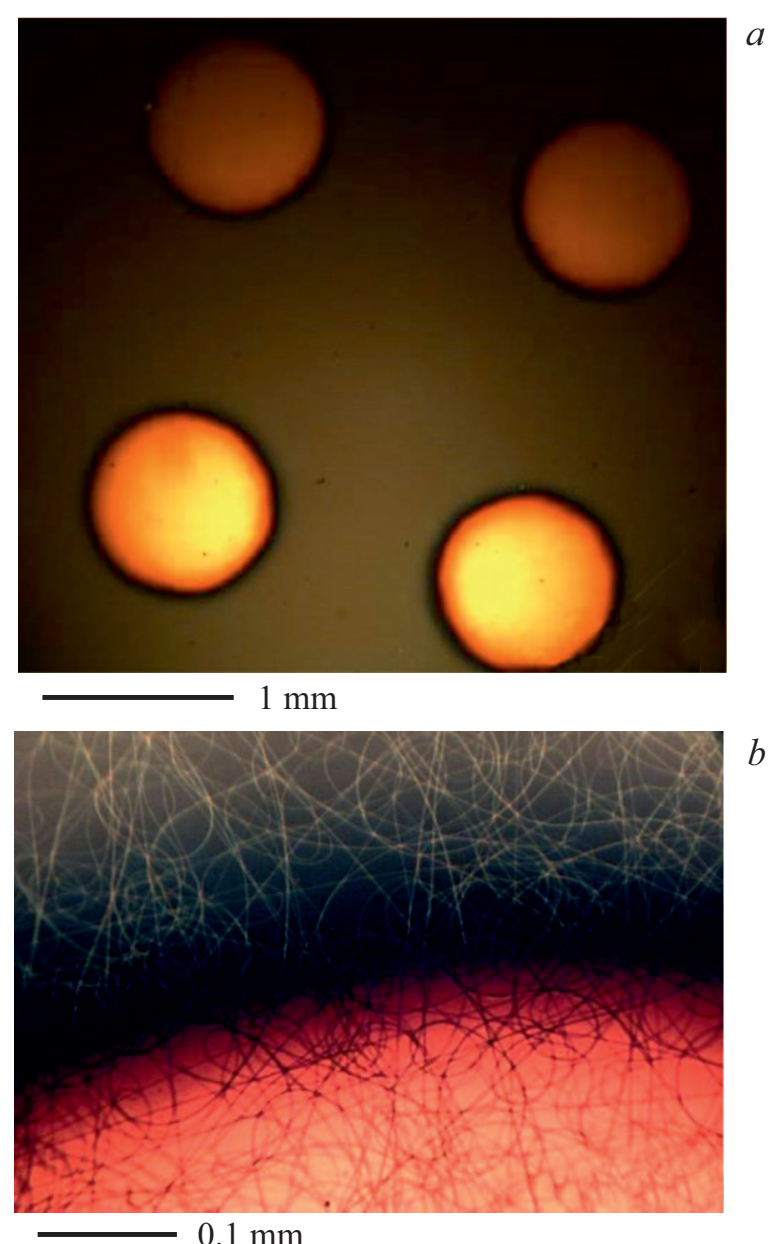

Рис. 5. Фотографии золотых контактов на нанонитях, сделанные с помощью оптического микроскопа с регистрацией изображения „ЛабоМет-2“: (a) увеличение $4 \times,(b)$ увеличение $40 \times$.

нанонитей $\mathrm{ZnO}$ (образец IZO9). Качественный фазовый анализ показывает, что после отжига образуется поликристаллическая фаза гексагонального оксида цинка со структурой вюрцита. Рентгенограмма нанонитей оксида индия соответствует кубической фазе $\mathrm{In}_{2} \mathrm{O}_{3}$ (рис. 4, $b$ ), а образец IZO5 $(\mathrm{In} / \mathrm{Zn}=50 / 50)$ представляет собой смесь фаз $\mathrm{ZnO}$ и $\mathrm{In}_{2} \mathrm{O}_{3}$ (рис. 4,c). Однако фаза $\operatorname{In}_{2} \mathrm{O}_{3}$ демонстрирует довольно четкие поликристаллические максимумы, в то время как рентгенограмма фазы ZnO на рис. 4,c скорее соответствует рентгеноаморфному материалу, что может быть связано с меньшим средним размером частиц (кристаллитов) $\mathrm{ZnO}$ по сравнению с зернами $\mathrm{In}_{2} \mathrm{O}_{3}$ в нитях IZO.

Для оценки чувствительности к УФ нанонитей оксида индия-цинка с различным атомным содержанием $\mathrm{In} / \mathrm{Zn}$ был использован источник слабого УФ излучения в области длин волн 230-290 nm „Фотон“, содержащий безэлектродную кварцевую ртутную лампу, смонтированную в отражателе, который помещался непосредственно над образцом на расстоянии $5 \mathrm{~cm}$. Энергетическая освещенность поверхности образца измерялась радиометром
ТКА-ПКМ 12 и составляла примерно $1 \mathrm{~mW} / \mathrm{cm}^{2}$ в диапазоне UVC $(\lambda=200-280 \mathrm{~nm}), 0.055 \mathrm{~mW} / \mathrm{cm}^{2}$ в диапазоне UVA $(320-400 \mathrm{~nm})$ и $0.026 \mathrm{~mW} / \mathrm{cm}^{2}$ в диапазоне UVB (280-320 nm). Здесь UVA, UVB и UVC - это спектральные диапазоны в соответствии со стандартом ISO [17].

Электрические свойства IZO нановолокон были исследованы с помощью источника-измерителя Keithley 2410. Для измерения ВАХ нанонити наносились на подложку $\mathrm{Si}-\mathrm{SiO}_{2}$, отжигались, а сверху через маску напылялись золотые контакты. Полученная конструкция изображена на рис. 5. Напыление золотых контактов производилось на установке Cressington 108 AUTO в автоматическом режиме. Диаметр нанесенных контактов составляет порядка $1 \mathrm{~mm}$, а расстояние между ними варьирует в пределах $1-1.5 \mathrm{~mm}$.

\section{Результаты и обсуждение}

На рис. 6, $а$ представлены ВАХ полученных образцов с различными атомными соотношениями In и $\mathrm{Zn}$ при их
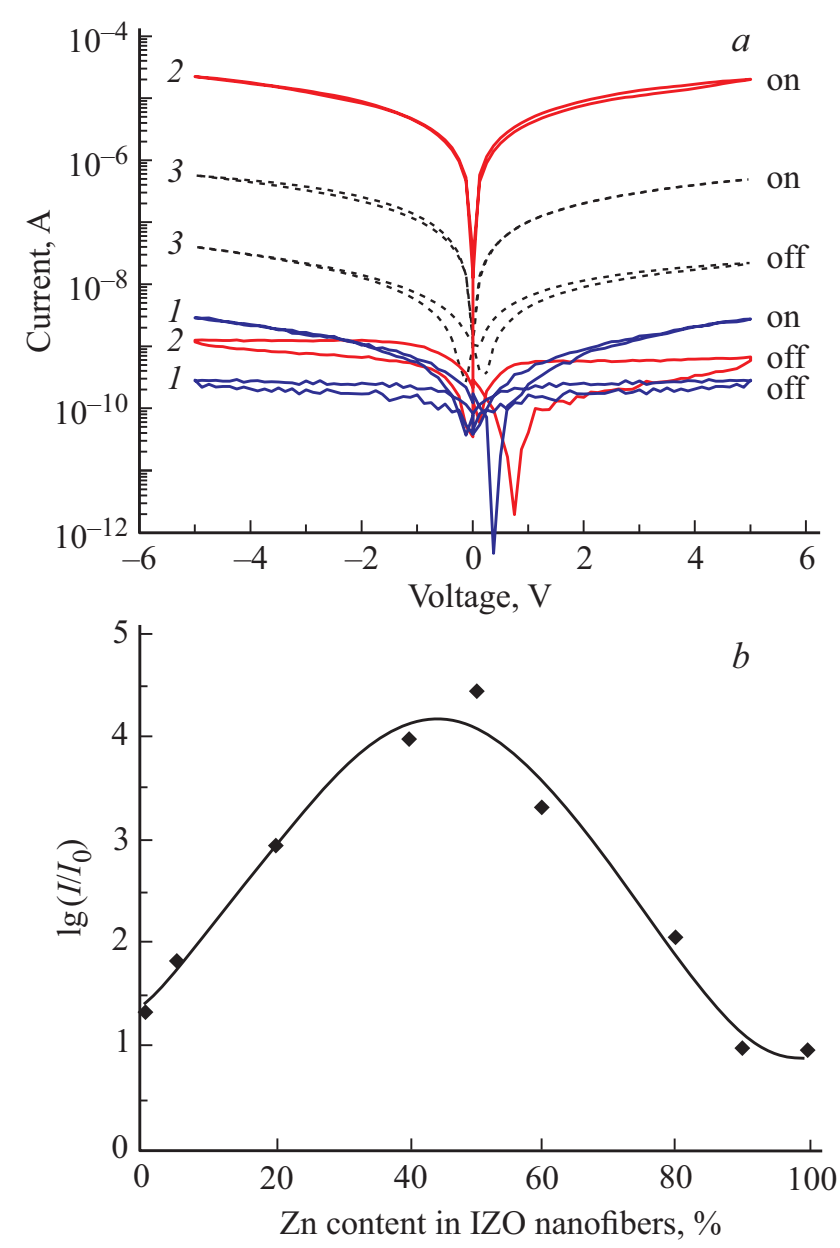

Рис. 6. (a) ВАХ образцов с различными атомными соотношениями In и $\mathrm{Zn}\left(1-\mathrm{ZnO}, 2-\mathrm{In}: \mathrm{Zn}=1: 1,3-\operatorname{In}_{2} \mathrm{O}_{3}\right)$ при естественной освещенности (off) и при их облучении УФ (on); (b) чувствительность к УФ излучению нанонитей IZO при различных соотношениях компонент. 

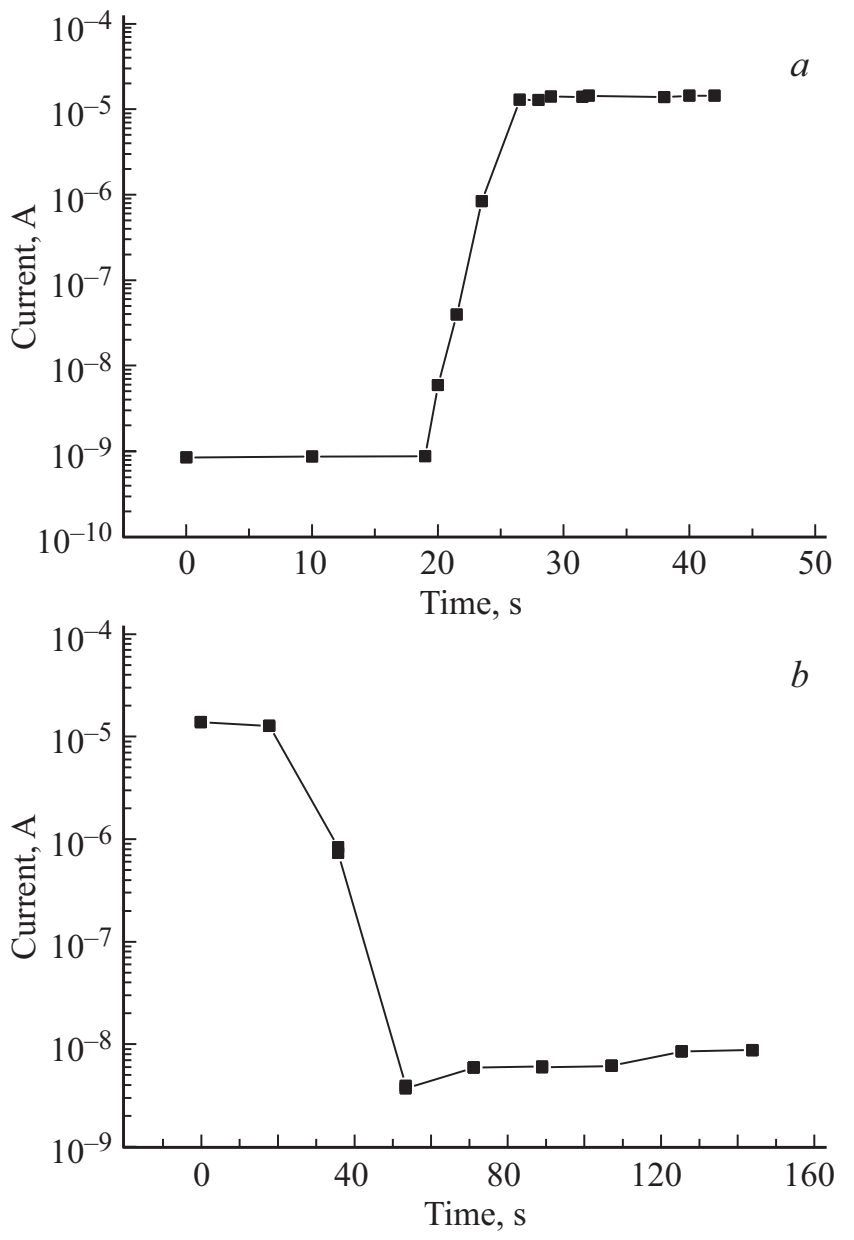

Pис. 7. (a) Нарастание тока в образце IZO с содержанием индия 50\% после включения источника УФ излучения; $(b)$ спад тока в том же образце после выключения УФ излучения.

облучении УФ и при естественной освещенности. Видно, что ток через образцы при УФ облучении увеличивается (рост фототока по сравнению с темновым составляет от 1 до 4 порядков для образцов разного состава), что означает соответственное падение сопротивления нанонитей.

На рис. $6, b$ показана зависимость относительной чувствительности образцов к УФ излучению от атомных соотношений In и $\mathrm{Zn}$. За чувствительность в данном случае принимается отношение тока при освещении образца к темновому току. Установлено, что максимальный рост проводимости достигается при соотношении In: $\mathrm{Zn}=1: 1$. У таких нитей проводимость возрастает на 4.5 порядка.

Проводимость нанонитей при включении и выключении источника УФ излучения возрастает и спадает относительно медленно (рис. 7). Времена нарастания и спада тока составляли около $6 \mathrm{~s}$ и $50 \mathrm{~s}$ соответственно.

Медленные повышение и спад проводимости могут быть связаны с фотохимическими процессами десорбции-адсорбции кислорода с поверхностей нитей. Молекулы кислорода из окружающей среды легко аб- сорбируются на поверхности нанонитей путем захвата свободных электронов из зоны проводимости, при этом молекулы становятся отрицательно заряженными ионами. Под воздействием УФ излучения в нанонитях IZO генерируются электронно-дырочные пары. Далее фотогенерируемые дырки рекомбинируют с адсорбированными ионами кислорода с образованием молекул кислорода, которые затем десорбируют с поверхности нанонитей [18]. Одновременно происходит увеличение числа электронов в зоне проводимости. Под действием приложенного напряжения смещения свободные электроны движутся к аноду, и возникает фототок. Чем больше площадь поверхности нанонитей IZO, тем больше скорости адсорбции и десорбции молекул кислорода с их поверхности при УФ облучении и соответственно больше фототок. При отключении источника УФ кислород из воздуха адсорбируется на поверхность нитей, захватывает избыточные электроны из зоны проводимости, и сопротивление нитей постепенно возрастает до начального значения.

Для проверки влияния кислорода на проводимость один из образцов (IZO3) был помещен в вакуумную камеру $(p=5 \mathrm{~Pa})$. Откачка воздуха не привела к существенному изменению начального сопротивления, но при воздействии УФ конечное сопротивление образца в вакууме значительно меньше, чем при облучении на воздухе (рис. 8). Это объясняется большей скоростью десорбции молекул кислорода с поверхности в вакууме. При отключении УФ облучения сопротивление оставалось низким до тех пор, пока не напускали в камеру воздух. Таким образом, эксперименты в вакууме подтверждают, что уменьшение сопротивления нитей связано с процессами десорбции-адсорбции кислорода с их поверхности. Полученные результаты согласуются c [19], где нити $\mathrm{ZnO}$ были синтезированы сонохимическим методом. Отклик на УФ составлял около трех порядков, время отклика $33 \mathrm{~s}$, а время восстановления $244 \mathrm{~s}$. В вакууме 0.4 Ра время восстановления увеличивалось до нескольких десятков минут.

В заключение отметим, что в целом ряде работ показано усиление чувствительности $\mathrm{ZnO}$ к УФ излу-

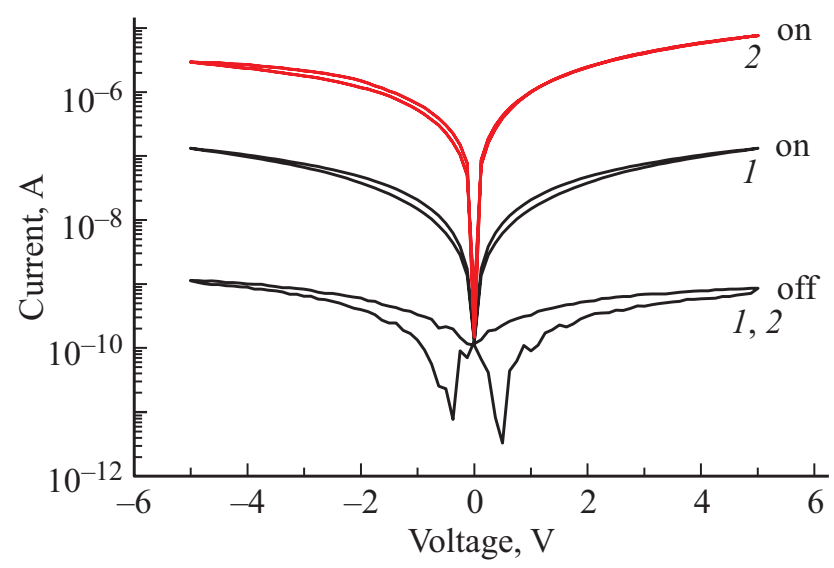

Рис. 8. BAX образца IZO3 на воздухе (1) и в вакуумной камере (2); off - без облучения, on - при облучении УФ. 
чению за счет легирования различными элементами, такими как индий $[13,14]$, ванадий [20], магний [21], алюминий $[18,22,23]$, галлий [23], олово [24], марганец [25], никель [26] и др. Для объяснения этих эффектов были предложены различные механизмы. В частности, повышение чувствительности к УФ излучению в $\mathrm{ZnO}: \mathrm{V}$ объясняется захватом и удалением электронов в дефектных состояниях, связанных с $\mathrm{V}^{4+}$ и $\mathrm{V}^{5+}$ [20]. Усиленный отклик наночастиц $\mathrm{ZnO}$, легированных $\mathrm{Mg}$, связан с неспаренными электронами, дающими вклад в фототок [21]. В работе [23] высокая чувствительность фотоприемников на основе $\mathrm{ZnO}$, легированных $\mathrm{Al}$ и $\mathrm{Ga}$, объясняется его высокой фотопроводимостью, а авторы [22] полагают, что в $\mathrm{ZnO}$, легированном $\mathrm{Al}$, увеличение фототока обусловлено увеличением количества дефектов (за счет введения алюминия), которые влияют на подвижность электронов. В работе [24] максимальный фотоотклик наблюдался при концентрации олова 7 wt.\% в ZnO. Было высказано предположение, что ненасыщенные связи через кристаллографическую плоскость (101) $\mathrm{ZnO}$ в таких легированных образцах могут служить предпочтительными местами для адсорбции молекул $\mathrm{O}_{2}$, что и приводит к высокому УФ фотоотклику [24]. Вопрос о том, какие из этих механизмов участвуют в повышении чувствительности к УФ излучению в нашем случае (рис. 6, $b$ ), по-видимому, требует дополнительного изучения. Кроме того, следует учитывать эффекты фазового расслоения для образцов с высоким содержанием индия, поскольку сегрегация индия, вероятно, происходит в образцах IZO4 и IZO5 в виде оксида индия на границах зерен $[16,27]$, а материал нановолокон может, таким образом, представлять собой смесь фаз, включающую как $\operatorname{In}_{2} \mathrm{O}_{3}$, так и IZO с высоким содержанием In. Этот вывод подтверждается также данными РСА на рис. 4, c.

\section{Заключение}

В работе описана технология получения нанонитей оксида индия-цинка с различным соотношением компонентов $(\mathrm{In} / \mathrm{Zn})$ методом электроспиннинга. Показано, что наибольшей чувствительностью к УФ излучению обладают образцы с содержанием индия порядка 50 at.\%. Приращение фототока относительно темнового тока составляет в этом случае более 4 порядков величины, что находится на уровне или выше тех значений, которые известны из литературы как для нанонитей $\mathrm{ZnO}$, так и для пленок оксида цинка, легированного различными элементами. Время нарастания и спада фототока при включении и соответственно выключении источника УФ излучения составляет 60 и $500 \mathrm{~s}$, однако достигнутые в [14] характерные времена срабатывания на уровне единиц секунд в аналогичных структурах позволяют надеяться, что при соответствующей оптимизации технологии параметры быстродействия могут быть улучшены. Полученные результаты указывают на то, что нанонити IZO могут найти применение в качестве чувствительных элементов датчиков УФ излучения, демонстрирующих такие параметры как, в частности, чувствительность, на уровне или лучше мировых аналогов датчиков УФ на основе оксидов металлов. Достоинством таких сенсоров являлась бы экономичность, учитывая низкую стоимость материала, простоту конструкции и очевидную дешевизну производства (жидкофазный золь-гель метод получения прекурсоров, электроспиннинг, не требующий дорогостоящего технологического оборудования).

\section{Благодарности}

Авторы выражают благодарность Л.А. Луговской за помощь в проведении рентгенофазового анализа образцов.

\section{Финансирование работы}

Работа выполнена при финансовой поддержке Минобрнауки России в рамках реализации государственного задания № 16.5857.2017/8.9.

\section{Конфликт интересов}

Авторы заявляют, что у них нет конфликта интересов.

\section{Список литературы}

[1] Ополченщев А.М., Задорожнная Л.А., Брискина Ч.М. u $ә р$. // Опт. и спектр. 2018. Т. 125. № 4. C. 501-506. Opolchentsev A.M., Zadorozhnaya L.A., Briskina Ch.M et. al. // Opt. Spectrosc. 2018. V. 125. N 4. P. 522-527.

[2] Özgür Ü, Alivov Ya.I., Liu C., Teke A., Reshchikov M.A., Doğan S., Avrutin V., Cho S.-J., Morkos H. // J. Appl. Phys. 2005. V. 98. P. 041301.

[3] Leonardi S.G. // Chemosensors. 2017. V. 5. N 2. P. 17-45. DOI: $10.3390 /$ chemosensors 5020017

[4] Воробьева Н.А. Автореф. канд. дисс. М., 2015. 180 с.

[5] Shyju G.J., Roy S.D.D., Chinnappanadar S. // Materials Science Forum. 2011. V. 671. P. 21-45.

[6] Saji K.J., Jayaraj M.K. Oxide Thin Film Transistors. N. Y: Nova Science Publishers, 2017.

[7] Cheremisin A.B., Kuznetsov S.N., Stefanovich G.B. // AIP Advances. 2015. V. 5. P. 117124.

[8] Belyaev M., Putrolaynen V., Velichko A., Markova N.// ECS J. Solid State Science and Technology. 2016. V. 5. N 3. P. Q92Q97.

[9] Wang J., Chen Y., Kong L.-A., Fu Y., Gao Y., Sun J. // Appl. Phys. Lett. 2018. V. 113. P. 151101.

[10] Chen K.-L., Jiang G.-J., Chang K.-W., Chen J.-H., Wu C.-H. // Analytical Chemistry Research. 2015. V. 4. P. 8-12.

[11] Гайдук Ю.С., Охманюк М.С., Савицкий А.А., Таратын И.А. // Вестник БГУ. Сер. 2. 2015. № 3. С. 8-12.

[12] Yang D.J., Whitfield G.C., Cho N.G., Choa P.-S., Kim I.-D., Saltsburg H.M., Tuller H.L. // Sens. Actuators B. 2012. V. 171-172. P. 1166-1171.

[13] Wu Y., Girgis E., Stróm V., Voit W., Belova L., Rao K.V. // Phys. Status Solidi A. 2011. V. 208. N 1. P. 206-209.

[14] Young S.-J., Liu Y.H. // IEEE Transactions on Electron Devices. 2016. V. 63. N 8. P. 3160-3164. 
[15] Березина О.Я., Кириенко Д.А., Маркова Н.П., Пергамент А.Л. // ЖТФ. 2015. Т. 85. Вып. 9. С. 105. Berezina O.Ya. , Kirienko D.A., Markova N.P., Pergament A.L. // Tech. Phys. 2015. V. 60. N 9. P. 1361-1366.

[16] Lotus A.F. Dissertation Doctor of Philosophy. The Graduate Faculty of The University of Akron, 2009.

[17] „ISO 21348 Definitions of Solar Irradiance Spectral Categories“. http://www.spacewx.com/pdf/SET_21348_2004.pdf

[18] Mamat M.H., Khusaimi Z., Zahidi M.M., Mahmood M.R. // Jpn. J. Appl. Phys. 2011. V. 50. N 6S. P. 06GF05.

[19] Nayak A.P., Lin T.-C., Lam D., Kaya S., Islam M.S. // Nanoscience and Nanotechnology Letters. 2012. V. 4. N 10. P. 977-982.

[20] Srivastava T., Bajpai G., Rathore G., Liu S.W., Biring S., Sen S. // J. Appl. Phys. 2018. V. 123. P. 161407.

[21] Alam M.S., Manzoor U., Mujahid M., Bhatti A.S. // J. Sensors. 2016. V. 2016. P. 8296936.

[22] Chongsri K., Pecharapa W. // Energy Procedia. 2014. V. 56. P. 554-559.

[23] Tsay C.-Y., Hsu W.-T. // Materials. 2017. V. 10. P. 1379.

[24] Kumar M., Bhatt V., Abhyankar A.C., Kim J., Kumar A., Yun J.-H. // Sensors and Actuators A. 2018. V. 270. P. $118-126$.

[25] Sugumar R., Angappane S. // Superlattices and Microstructures. 2017. V. 110. P. 57-67.

[26] Elkamel I.B., Hamdaoui N., Mezni A., Ajjel R., Beji L. // RSC Advances. 2018. V. 8. P. 32333-32343.

[27] Lotus A.F., Kang Y.C., Ramsier R.D., Chase G.G. // J. Vac. Sci. Technol. B. 2009. V. 27. N 6. P. 2331-2336. 